\title{
Hearing Abnormalities in Patients with Osteoarthritis

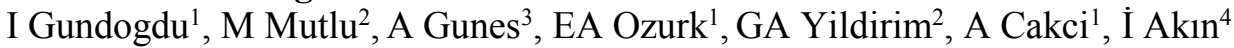

\begin{abstract}
Objective: This study was designed to compare the prevalence of hearing abnormalities between the patients with osteoarthritis $(\mathrm{OA})$ and an age and gender-matched control group without OA.

Material and methods: Thirty-six consecutive patients (72 ears) admitting the outpatient clinics of physical therapy and rehabilitation with the diagnosis of hand and knee osteoarthritis according to ACR criteria and Kellgren-Lawrence grading system, and age and sex-matched 30 healthy volunteers (60 ears), were included in the study. Distortion product otoacoustic emissions (DPOAE) values between $1 \mathrm{kHz}-4 \mathrm{kHz}$, tympanometric examination results, stapes reflex values, speech reception threshold (SRT) and speech discrimination (SD) values, pure-tone values between 250 and $8000 \mathrm{~Hz}$ and high-frequency values at $10000 \mathrm{~Hz}, 12500 \mathrm{~Hz}$ and $16000 \mathrm{~Hz}$ were analyzed. Statistical comparisons between both groups were performed using chi-square test and Mann Whitney- U test.
\end{abstract}

Results: The mean age of 36 patients with OA and 30 healthy controls was $53.78 \pm 6.12$ and $53.30 \pm$ 4.48 years respectively. Mean duration of osteoarthritis was $2.89 \pm 1.68$ years. In the evaluation of hearing frequencies of the patients between 4000 and $12500 \mathrm{~Hz}$, pure tone average results and tympanometric examination results, a statistically significant difference was found relative to the control group $(\mathrm{p}<0.05)$. There was no statistically significantly difference between DPOAE values of the groups.

Conclusion: Our current study demonstrates strong evidence for sensorineural hearing loss in patients with OA.

Keywords: Cochlear function, hearing loss, osteoarthritis, tympanometry

From: ${ }^{1}$ Department of Physical Therapy and Rehabilitation, Diskapi Yildirim Beyazit Education and Research Hospital, Ankara, Turkey. ${ }^{2}$ Department of Otorhinolaryngology, Diskapi Yildirim Beyazit Education and Research Hospital, Ankara, Turkey. ${ }^{3}$ Department of Otorhinolaryngology, Golbasi Hasvak State Hospital, Ankara, Turkey. ${ }^{4}$ Department of Otorhinolaryngology, Kafkas University Medical School, Kars, Turkey

Correspondence: Dr I Gundogdu, Department of Physical Therapy and Rehabilitation, Diskapi, Yildirim Beyazit Education and Research Hospital, Ankara, Turkey. E-mail: ibrahimftr@gmail.com 


\section{INTRODUCTION}

Osteoarthritis (OA) and hearing loss are the most common causes of chronic disability in older adults (1-3). OA is also the most common joint disease and is the major cause of pain and disability throughout the world (3). Previous studies have shown that the chronic diseases were associated with hearing loss in adults (4). In 2007, Rawool et al. reported the higher prevalence of middle ear abnormalities in patients with OA compared to controls (1), however, little is known about auditory manifestations in patients with OA.

Several studies have also reported an association between inflammatory diseases and hearing loss. Sensorineural, conductive, and mixed type hearing loss in patients with inflammatory diseases such as rheumatoid arthritis (RA) (5-8), ankylosing spondylitis (AS) $(9,10)$, inflammatory bowel disease (11), Behcet's disease (12) and psoriatic arthritis (PsA) (13) have been reported. Arthritis of the joints of the ossicular chain in the middle ear, immune complex-mediated vasculitis of the inner ear and ototoxic effects of drugs used for the treatment have been generally accounted for hearing loss in inflammatory diseases.

Although $\mathrm{OA}$ is known as a degenerative, non-inflammatory disease, the inflammatory response and low grade chronic systemic inflammation play an important role in the pathogenesis of OA (14-22). Regarding OA cartilage destruction, it has been shown that upregulation of m-RNA of several proinflammatory cytokines, increased expression of genes for metalloproteinases, COX-2, IL-1, IL-8, tissue growth factor beta have a role in the pathogenesis of OA $(14-20,23)$.

OA can affect hearing via a number of different mechanisms such as; osteoarthritis of the synovial incudostapedial and incudomalleolar joints, causing a conductive hearing loss, local inflammatory process could cause destruction of the cochlear hair cells, causing sensorineural hearing loss and drugs which are used to treat osteoarthritis could affect the hearing. 
Therefore, this study was designed to compare the prevalence of conductive and sensorineural hearing abnormalities in patients with osteoarthritis and an age and gender matched control group without osteoarthritis. We compared distortion-product otoacoustic emission values (DPOAE) as a measure of acoustic distortion, tympanometry, stapes reflex, speech reception threshold (SRT), speech discrimination (SD) and audiogram values between 125 and $16.000 \mathrm{~Hz}$ frequencies, between the patient and the control groups.

\section{MATERIAL AND METHODS}

\section{Study population}

This study was carried out in physical medicine and rehabilitation and otolaryngology clinics of tertiary care hospital. Our study was approved by the Local Ethics Committee and informed consent forms were obtained from the patients and controls.

The participants in our study were consecutive patients attending physical therapy and rehabilitation (PMR) outpatient clinics of our hospital over a period of 12 months, younger than 65 years, who fulfilled the diagnosis of hand and knee OA according to American College of Rheumatology (ACR) clinical and laboratory criteria and grade $\geq 1$ knee OA according to Kellgren-Lawrence grading system (24-26) and age and sex-matched healthy volunteers who agreed to the study were enrolled consecutively.

All the patients and controls underwent careful systematic history taking session with special emphasize on the joint and hearing complaints. Patients and controls with a history of congenital ear disease, inflammatory disease, family history of hearing loss, otologic surgery, head and neck trauma, neoplasm of the brain and ear, tympanic membrane perforation, ototoxic drug use (eg; salicylates), occupational noise exposure, Ménière's syndrome, neurologic disease, cerebrovascular disease, metabolic disease, renal disease, recurrent otitis 
media, having suffered upper respiratory airway infection $<=30$ days before study entry and otoscopic evidence of ear pathology were excluded from the study. Healthy controls with a history of osteoarthritis, hard tissue enlargement of distal and proximal interphalangeal joints of the hand or complained of joint pain were excluded from the study. All of the patients with OA in our study had been treated with or were using one of the nonsteroidal antiinflammatory drugs and/or paracetamol, three of them were using glucosamine and chondroitin sulfate additionally. The same PMR specialist performed the rheumatologic evaluations of all patients and controls.

Based on these inclusion and exclusion criteria, 36 patients with OA (72 ears), and 30 age and sex-matched healthy controls (60 ears) were assessed in this study.

During the recruitment process, 10 patients with OA were excluded; 4 patients because of positive otoscopy, 3 patients because of laboratory results and 3 patients because of metabolic disease. Also, 3 control participants were excluded because of occupational noise exposure history.

\section{Audiologic evaluations}

All patients and healthy controls underwent complete ear, nose and throat examination. Any participants who had significant amount of cerumen, scarred or perforated tympanic membrane were excluded from the study. Then, audiologic investigations were carried out in an audiology unit of our hospital. All patients and controls received audiometry (Madsen Astera, Denmark), tympanometry (Grason Stadler, USA) and DPOAE (Neurosoft, Russia) studies. DPOAE values between $1 \mathrm{kHz}-4 \mathrm{kHz}$, tympanometric examination results, Stapes reflex, SRT and SD values, pure-tone audiometry values between 250 and $8000 \mathrm{~Hz}$ and highfrequency values at $10000 \mathrm{~Hz}, 12500 \mathrm{~Hz}$ and $16000 \mathrm{~Hz}$ were analyzed. All DPOAE and audiologic tests were performed in a soundproof room by a single specialist who was blinded 
to the study parameters. The rheumatologic and audiometric assessments were performed concomitantly.

\section{Statistical Analysis}

Normality of the continuous variables was assessed via the Shapiro-Wilk test. Descriptive statistics were expressed as mean \pm standard deviation. Bivariate associations were determined using the chi-square test for categorical variables, and the Mann-Whitney U test was used for the comparison of non-normally distributed continuous variables. Statistical results with a value of $\mathrm{p}<0.05$ were considered statistically significant. Statistical analysis was performed using the Statistical Package for the Social Sciences 15.0 (SPSS, Inc.; Chicago, IL, USA) version for Windows.

\section{RESULTS}

The mean age of 36 patients ( 35 women and 1 man) with knee OA was $53 \pm 6,12$ years and that of the 30 controls ( 28 women and 2 men) was 53,30 \pm 4.48 years. No difference was found between patients and controls with respect to age or sex $(p<0.05)$. The mean duration of disease was $2.89 \pm 1.68$ years.

There was a significant difference between patient and control groups in pure tone average results and hearing thresholds at frequencies of $4000-6000-10000$ ve $12500 \mathrm{~Hz}$ for both ears, and at frequency of $8000 \mathrm{~Hz}$ for right ear $(\mathrm{P}<0,05)$ (Table 1).

SRT values were significantly different between patient and the control groups for both ears. SD values were also significantly different between patient and the control groups for left ear $(\mathrm{P}<0.05)$ (Table 2). 
DPOAE measurement findings in all frequencies showed no significant difference between the two groups $(\mathrm{p}>0.005)$. The mean DPOAE measurement results at frequencies of $1000-400 \mathrm{~Hz}$ are shown in Table 3.

There was a significant difference between the two groups in tympanometric and stapes reflex values $(\mathrm{P}<0.05)$ (Table 4, 5).

\section{DISCUSSION}

$\mathrm{OA}$ is the most common type of arthritis or degenerative disease affecting articular cartilage, bone and surrounding tissues and it is a leading cause of chronic disability (3). Pathogenesis of OA includes genetic, environmental, metabolic, and biomechanical factors (27). OA was initially considered as a degenerative non-inflammatory condition of elderly, but recent studies have demonstrated the role of cytokines and other mediators of inflammation in OA pathogenesis. (21,22). Mechanical stress and joint loading may appear to induce the expression of proinflammatory cytokines and matrix metalloproteinases $(14,15)$ causing increased release of cytokines such as IL-1, IL-6 and TNF- $\alpha$. It was also shown to stimulate the secretion of the eicosanoids, nitric oxide (NO.) and superoxide anion (O2.-) which contribute to the inflammation and the joint destruction $(16,17)$.

The role of reactive oxygen species (ROS) and nitric oxide (NO) in the pathogenesis of osteoarthritis have been discussed in previous studies. Excessive levels of ROS and NO could play an important role in catabolic process of osteoarthritis and could also contribute to chondrocyte death by causing oxidative damage to proteins, lipids, and DNA, which are consistent with the knowledge that low grade chronic systemic inflammation contributes to the pathogenesis OA. (18-20). 
The etiology of SNHL is also multifactorial, with over-exposure to noise, some drugs, immune-induced inflammation being common causes. Many researchers have also substantiated role of inflammatory cytokines (ie TNF- $\alpha$ ), ROS and NO, and the role of prolonged oxidative and cellular mechanisms, leading to cochlear injury and sensorineural hearing loss $(28,29)$. Other authors have reported the association between hearing loss and polymorphisms of genes encoding cytokines related to the inflammatory response (30). It has also been suggested that the sensorineural hearing loss may be a part of syndrome related to childhood onset progressive osteoarthritis associated with mutation in procollagen type-II gene (31).

The association between hearing impairment and inflammatory diseases such as; RA, AS, PsA, inflammatory bowel disease and Behcet's disease have been reported in recent studies (5-13). Rawool et al. (1) reported the association between conductive hearing loss and osteoarthritis but there have been no further studies conducted on whether these conditions have any relationship. The study's authors claimed that OA affecting the incudomalleal and incudostapedial joints, annular ligament attaching the stapes footplate to the oval window can cause middle ear abnormalities.

Regarding conductive hearing loss in inflammatory diseases, other studies also suggest the synovial involvement of the incudomalleal and incudostapedial joints, which are diarthrodes, as any other joint involvement in rheumatic diseases.

In our study, we did not found any middle ear abnormality, which can be partially explained in terms of the mean age difference between patient population of our study and Rawool et al.’s (1) study (66.06 yrs vs. $53.78 \pm 6,12$ years).

Rawool et al. also found that the patients with OA had higher prevalence of sensorineural hearing loss compared to control group, but results had not reached a statistically significant level. They emphasized the role of inflammatory process 
and immune deregulation involved in pathogenesis of $\mathrm{OA}$ as a cause of possible sensorineural hearing loss. They also speculated the role of drugs used in the treatment of OA. Majority of studies report that there is more sensorineural hearing loss caused by inner ear involvement in patients with inflammatory disease than in controls (5-10). The pathophysiological mechanism is poorly known but one of the most widely accepted theories propose vasculitis and neuritis manifestations of inflammatory diseases could affect the cochlea and eighth cranial nerve, thus causing sensorineural hearing loss. The experiment has also been used to illustrate the role of TNF- $\alpha$ inhibitors in the treatment of immune-mediated hearing loss (32). Ototoxic effects of drugs used for the treatment have also been accounted for this condition (5-10).

We found higher pure tone average results in the OA group compared with the controls for both ears. In addition, hearing thresholds at frequencies of 4000-6000-10000 ve $12500 \mathrm{~Hz}$ for both ears were also significantly higher in the OA group, supporting the sensorineural hearing abnormality, which also indirectly supports the role of low grade chronic systemic inflammation in OA pathogenesis.

In a study regarding relationship between high frequency hearing and DPOAEs, authors hypothesized that the otoacoustic emissions act as early determiners of cochlear dysfunction and it indicates the summed activity of an important portion of outer hair cells. In that study, analysis revealed that DPOAE levels at $4-8 \mathrm{~Hz}$ had significantly correlated with the PTA from 11.2 to $20 \mathrm{kHz}$, and the PTA for 4-8 Hz also correlated with PTA for ultra high frequency hearing. They found that ultra high frequency hearing accounted for only $14 \%$ of the variance in DPOAE levels at 4-8 Hz, but Pure tone average results had not contributed significantly to the DPOAE variance, and they concluded that the high frequency hearing influences DPOAE at lower frequencies before the pure tone thresholds can detect the change in outer hair cells (33). In our study, although we found a significant difference between 
groups regarding PTA and hearing frequencies between 4000-12500 Hz, there was no difference between groups in DPOAE at 1000-4000 Hz. Our findings did not support the relationship between otoacoustic emissions and hearing frequencies, and highlight the need for more research in this subject.

In the study performed by Amor-Dorado and colleagues (13) for sensorineural hearing abnormalities in patients with psoriatic arthritis, they found that the tympanometric and stapes reflex evaluations may be sensitive to cochlear dysfunction. In that study, patients with psoriatic arthritis also exhibited higher values of SRT than controls, but speech discrimination values were not different between groups. In our study, there was no significant difference among the groups for stapes reflex, and tympanogram pressure values were significantly different between groups. Similarly, we found that the SRT values were significantly higher in patients with OA than controls, which may contribute to cochlear dysfunction.

As strengths of our study, since age related sensorineural hearing abnormality can be expected in both the patient and age-matched control group included in the current study, we excluded patients older than 65 years, which might partially prevented the negative effects of old age on hearing acuity. In addition, since osteoarthritis occurs with aging, we included relatively younger patient and control group, which might also partially discard the possible inaccurate inclusion of undiagnosed and asymptomatic healthy controls with osteoarthritis.

The primary limitation of our study was a small sample size and its cross sectional design, which may influence the generalizability of our findings and we could not compare our data with follow-up results. However, they were representative of patients with OA that participate in clinical trials in age and gender, and our sample size was similar to other controlled studies related to hearing impairment in arthritis. Furthermore, we excluded patients using ototoxic drugs but we did not discuss the possible negative effects of drugs use 
in the OA, potential ototoxic effects of NSAID use on hearing functions is a limitation of our study. Future research should attempt to investigate the relationship between disease activity and hearing impairment.

\section{CONCLUSION}

Our findings suggest an association of OA and sensorineural hearing loss. To our knowledge, this is the second OA population report evaluating the audio vestibular system with multiple tests. Our study along with previous study by Rawool et al. may indicate that the assessment of hearing impairment among patients with OA.

In conclusion, significant differences in the pure-tone average values and hearing thresholds at $4000-12500 \mathrm{~Hz}$ detected in patients with OA demonstrate involvement of the functions of the inner ear. Clinicians who are involved in the management of OA should be aware of hearing impairment, which is itself a potential cause of severe disability. Therefore, we recommend performing audiological evaluations and taking necessary precautions in patients with OA.

\section{AUTHORS' NOTE}

The authors declare no conflict of interest. 


\section{REFERENCES}

1. Rawool VW, Harrington BT. Middle ear admittance and hearing abnormalities in individuals with osteoarthritis. Audiol Neurootol 2007; 12: 127-36.

2. Yang $\mathrm{CH}$, Schrepfer T, Schacht J. Age-related hearing impairment and the triad of acquired hearing loss. Biomed Res Int 2015; 2015: 617207.

3. Pereira D, Severo M, Santos RA, Barros H, Branco J, Lucas R, Costa L, Ramos E. Knee and hip radiographic osteoarthritis features: differences on pain, function and qu ality of life.Clin Rheumatol 2015 Oct 7. (Epub ahead of print)

4. Shiue I. Chronic diseases and life events accounted for 2-18\% population attributable risks for adult hearing loss: UK Adult Psychiatric Morbidity Survey, 2007. Eur Arch Otorhinolaryngol 2015 Jan 10. (Epub ahead of print)

5. Özkırış M, Kapusuz Z, Günaydın İ, Kubilay U, Pırtı İ, Saydam L. Does rheumatoid arthritis have an effect on audiovestibular tests? Eur Arch Otorhinolaryngol 2014; 271: $1383-7$.

6. Raut VV, Cullen J, Cathers G. Hearing loss in rheumatoid arthritis. J Otolaryngol 2001; 30: 289-94

7. Dikici O, Muluk NB, Tosun AK, Unlu“soy I. Subjective audiological tests and transient evoked otoacoustic emissions in patients with rheumatoid arthritis: analysis of the affecting hearing levels. Eur Arch Otorhinolaryngol 2009; 266:1719-26

8. Takatsu M, Higaki M, Kinoshita H, Mizushima Y, Koizuka I. Ear involvement in patients with rheumatoid arthritis. Otol Neurotol 2005; 26: 755-61

9. Amor-Dorado JC, Barreira-Fernandez MP, Vazquez-Rodriguez TR, Gomez-Acebo I, Miranda-Filloy JA, Diaz de Teran T, Llorca J, Gonzalez-Gay MA. Audiovestibular manifestations in patients with ankylosing spondylitis. Medicine (Baltimore). 2011; 90: $99-109$. 
10. Adam M, Erkan AN, Arslan D, Leblebici B, Ozlüoğlu L, Nafiz Akman M. Highfrequency sensorineural hearing loss in patients with ankylosing spondylitis:

isitan extrarticulerfeature of disease? Rheumatol Int 2008; 28: 413-7.

11. Kumar BN, Smith MS, Walsh RM, Green JR. Sensorineural hearing loss in ulcerative colitis. Clin Otolaryngol Allied Sci 2000; 25: 143-5.

12. Sonbay ND, Saka C, Tatlican S, et al. Audiological evaluation in patients with Behçet's disease. J Laryngol Otol 2014; 128: 694-7.

13. Amor-Dorado JC, Barreira-Fernandez MP, Pina T, Vázquez-Rodríguez TR, Llorca J, González-Gay MA Investigations into audiovestibular manifestations in patients with psoriatic arthritis. J Rheumatol 2014; 41: 2018-26.

14. Fujisawa T, Hattori T, Takahashi K, Kuboki T, Yamashita A, Takiga-wa M. Cyclic mechanical stres induces extracellular matrix degradation in cultured chondrocytes via gene expression of matrix metalloproteinases and interleukin-1. J.Biochem (Tokyo), 1999; 125: 966-75.

15. Honda K, Ohno S, Tanimoto K, Ijuin C, Tanaka N, Doi T et al. The effects of high magnitude cyclic tensile load on cartilage matrix metabolism in cultured chondrocytes. Eur. J. Cell Biol 2000; 79: 601-9.

16. Lee DA, Frean SP, Lees P, Bader DL. Dynamic mechanical compression influences nitric oxide production by articular chondrocytes seeded in agarose. Biochem Biophy Res Commun 1998; 251: 580-5.

17. Miyagi I, Kikuchi H, Hamanishi C, Tanaka S. Autodestruction of the articular cartilage and free radical mediators. J Lab Clin Med 1998; 131: 146-50.

18. Li D, Xie G, Wang W. Reactive oxygen species: the 2-edged sword of osteoarthritis. Am J Med Sci 2012; 344: 486-90. 
19. Haklar U, Yüksel M, Velioğlu A, Turkmen M, Haklar G, Yalçin A.S. Oxygen radicals and nitric oxide levels in chondral or meniscal lesions or both. Clin Orthop Relat Res, 2002; 403: 135-42.

20. Loeser RF. Aging and osteoarthritis: the role of chondrocyte senescence and aging changes in the cartilage matrix. Osteoarthritis Cartilage. 2009; 17: 971-9.

21. Gomes WF, Lacerda AC, Mendonca VA, Arrieiro AN, Fonseca SF, Amorim MR, Rocha-Vieira E, Teixeira AL, Teixeira MM, Miranda AS, Coimbra CC, Brito-Melo E. Effect of aerobic training on plasma cytokines and soluble receptors in elderly women with knee osteoarthritis, in response to acute exercise. Clin Rheumatol 2010; 31: 75966.

22. Calich AL, Domiciano DS, Fuller R.Osteoarthritis: can anti-cytokine therapy play a role in treatment? Clin Rheumatol 2010; 29: 451-5.

23. Gruber J, Vincent TL, Hermansson $M$ et al. Induction of interleukin-1 in articular cartilage by explantation and cutting. Arthritis Rheum 2004; 50: 2539 -46.

24. Kellgren JH, Lawrence JS. Radiological assessment of osteo-arthrosis. Ann Rheum Dis.1957; 16: 494-502.

25. Altman R, Alarcón G, Appelrouth D, Bloch D, Borenstein D, Brandt K, Brown C, Cooke TD, Daniel W, Gray R et al. The American College of Rheumatology criteria for the classification and reporting of osteoarthritis of the hand. Arthritis Rheum 1990; 33: 1601-10.

26. Altman RD, Asch E, Bloch D, Bole G, Borenstein D, Brandt K, et al. Development of criteria for the classification and reporting of osteoarthritis. Classification of osteoarthritis of the knee. Diagnostic and Therapeutic Criteria Committee of the American Rheumatism Association. Arthritis Rheum1986; 29: 1039-49. 
27. Henry J, Mankin D: Pathogenesis of Osteoarthritis. Kelley's Textbook of Rheumatology, sixth edition, volume II, Saunders Company, 2001.

28. Wong AC, Ryan AF. Mechanisms of sensorineural cell damage, death and survival in cochlea. Front Aging Neurosci 2015; 7: 58.

29. Kamogashira T, Fujimoto C, Yamasoba T. Reactive oxygen species, apoptosis, and mitochondrial dysfunction in hearing loss. Front Cell Neurosci 2015; 9: 276.

30. Uchida Y, Sugiura S, Ueda H, Nakashima T, Ando F, Shimokata H. The association between hearing impairment and polymorphisms of genes encoding inflammatory mediators in Japanese aged population. Immun Ageing 2014; 11: 18.

31. Löppönen T, Körkkö J, Lundan T, Seppänen U, Ignatius J, Kääriäinen H. Childhoodonset osteoarthritis, tall stature, and sensorineural hearing loss associated with Arg75Cys mutation in procollagen type II gene (COL2A1). Arthritis Rheum. 2004; 51: 92532.

32. Wang X, Truong T, Billings PB, Harris JP, Keithley EM: Blockage of immunemediated inner ear damage by etanercept. Otol Neurotol 2003; 24: 52-7

33. Arnold DJ, Losbury-Martin B, Martin GK. High-frequency hearing influences lowerfrequency distortion-product otoacoustic emissions. Arch Otolarygol Head Neck Surgery 1999; 125: 215-22. 
Table 1. Pure tone average results and hearing thresholds between $4000 \mathrm{~Hz}-16000 \mathrm{~Hz}$

\begin{tabular}{|c|c|c|c|}
\hline & $\begin{array}{l}\text { OA group }(\mathrm{dB}) \\
(\text { mean } \pm \mathrm{SD})\end{array}$ & $\begin{array}{l}\text { Control group }(\mathrm{dB}) \\
(\text { mean } \pm \mathrm{SD})\end{array}$ & $\mathrm{p}$ value \\
\hline $4000 \mathrm{~Hz} \mathrm{R}$ & $22,36 \pm 10,035$ & $15,00 \pm 8,305$ & 0,010 \\
\hline $4000 \mathrm{~Hz} \mathrm{~L}$ & $26,39 \pm 12,962$ & $16,33 \pm 8,703$ & $<0,001$ \\
\hline $6000 \mathrm{~Hz} \mathrm{R}$ & $30,97 \pm 15,713$ & $20,83 \pm 10,178$ & 0,005 \\
\hline $6000 \mathrm{~Hz} \mathrm{~L}$ & $31,94 \pm 13,217$ & $23,67 \pm 11,290$ & 0,003 \\
\hline $8000 \mathrm{~Hz} \mathrm{R}$ & $25,28 \pm 18,045$ & $17,00 \pm 12,077$ & 0,028 \\
\hline $8000 \mathrm{~Hz}$ L & $38,42 \pm 24,593$ & $34,17 \pm 15,227$ & 0,355 \\
\hline $10000 \mathrm{~Hz} \mathrm{R}$ & $37,78 \pm 20,335$ & $26,67 \pm 19,268$ & 0,007 \\
\hline $10000 \mathrm{~Hz} \mathrm{~L}$ & $43,06 \pm 25,079$ & $29,17 \pm 20,514$ & 0,013 \\
\hline $12500 \mathrm{~Hz} \mathrm{R}$ & $56,94 \pm 17,537$ & $38,83 \pm 22,155$ & 0,011 \\
\hline $12500 \mathrm{~Hz} \mathrm{~L}$ & $60,56 \pm 16,766$ & $44,00 \pm 24,011$ & 0,008 \\
\hline $16000 \mathrm{~Hz} \mathrm{R}$ & $57,64 \pm 6,707$ & $56,00 \pm 7,922$ & 0,329 \\
\hline $16000 \mathrm{~Hz} \mathrm{~L}$ & $57,78 \pm 5,404$ & $56,00 \pm 9,773$ & 0,987 \\
\hline PTA (L- AC) & $16,08 \pm 6,699$ & $11,50 \pm 4,554$ & 0,002 \\
\hline PTA $(\mathrm{R}-\mathrm{AC})$ & $15,78 \pm 5,550$ & $11,73 \pm 4,697$ & 0,001 \\
\hline PTA (L-BC) & $14,00 \pm 6,676$ & $10,20 \pm 4,097$ & 0,016 \\
\hline PTA (R-BC) & $13,78 \pm 6,090$ & $10,00 \pm 3,948$ & 0,006 \\
\hline
\end{tabular}

OA; osteoarthritis, R; right, L; left, PTA; Pure tone average, AC; air conduction, $\mathrm{BC}$; bone conduction 
Table 2. Speech reception threshold and speech discrimination values

\begin{tabular}{llll}
\hline & $\begin{array}{l}\text { OA group }(\mathrm{dB}) \\
(\text { mean } \pm \text { SD) }\end{array}$ & $\begin{array}{l}\text { Control group }(\mathrm{dB}) \\
(\text { mean } \pm \text { SD) }\end{array}$ & p value \\
\hline SRT (L) (dB) & $16,67 \pm 6,437$ & $11,33 \pm 2,916$ & $<0,001$ \\
SRT (R) (dB) & $16,53 \pm 5,955$ & $11,50 \pm 3,511$ & $<0,001$ \\
SD (L) (\%) & $98,44 \pm 3,484$ & $99,87 \pm, 730$ & 0,016 \\
SD (R) (\%) & $98,56 \pm 3,193$ & $99,73 \pm 1,015$ & 0,073 \\
\hline
\end{tabular}

OA; osteoarthritis, SRT; speech reception threshold, SD; speech discrimination, R; right, L; left

Table 3. DPOAE values

\begin{tabular}{|c|c|c|c|}
\hline & $\begin{array}{l}\text { OA group }(\mathrm{dB}) \\
(\text { mean } \pm \mathrm{SD})\end{array}$ & $\begin{array}{l}\text { Control grocipon } \\
\text { (mean } \pm \text { SDOme }\end{array}$ & $\begin{array}{l}\text { group }(\mathrm{dB}) \\
\text { tpSralue }\end{array}$ \\
\hline DPOAE (L - $1000 \mathrm{~Hz})$ & $6,903 \pm 5,8084$ & $8,913 \pm 6,4839$ & 0,234 \\
\hline DPOAE (L - $1500 \mathrm{~Hz})$ & $\begin{array}{l}11,472 \pm 7,606 \\
6\end{array}$ & $11,463 \pm 7,8057$ & 0,854 \\
\hline DPOAE (L - $2000 \mathrm{~Hz})$ & $\begin{array}{l}14,306 \pm 7,697 \\
1\end{array}$ & $14,390 \pm 6,7791$ & 0,854 \\
\hline DPOAE (L - $3000 \mathrm{~Hz})$ & $\begin{array}{l}13,375 \pm 8,381 \\
9\end{array}$ & $15,293 \pm 8,4618$ & 0,341 \\
\hline DPOAE (L - $4000 \mathrm{~Hz})$ & $\begin{array}{l}11,017 \pm 7,800 \\
5\end{array}$ & $13,707 \pm 8,4930$ & 0,089 \\
\hline DPOAE (R - $1000 \mathrm{~Hz})$ & $7,525 \pm 5,9824$ & $7,437 \pm 6,5335$ & 0,939 \\
\hline DPOAE (R - $1500 \mathrm{~Hz})$ & $\begin{array}{l}11,833 \pm 7,373 \\
9\end{array}$ & $12,443 \pm 7,6817$ & 0,650 \\
\hline DPOAE (R - $2000 \mathrm{~Hz})$ & $\begin{array}{l}14,856 \pm 7,573 \\
2\end{array}$ & $14,117 \pm 6,5183$ & 0,581 \\
\hline DPOAE (R - $3000 \mathrm{~Hz})$ & $15,37 \pm 6,903$ & $16,42 \pm 6,310$ & 0,479 \\
\hline DPOAE (R - $4000 \mathrm{~Hz})$ & $\begin{array}{l}15,244 \pm 9,311 \\
7\end{array}$ & $17,847 \pm 9,1052$ & 0,241 \\
\hline
\end{tabular}

OA; osteoarthritis, DPOAE; distortion product otoacoustic emissions, R; right, L; left 
Table 4. Tympanometric examination results.

\begin{tabular}{llllll}
\hline & $\begin{array}{l}\text { Tympanogram } \\
\text { pressure }(\mathrm{L}) \\
(\mathrm{daPa}) \\
(\text { mean } \pm \mathrm{SD})\end{array}$ & $\begin{array}{l}\text { Tympanogram } \\
\text { pressure }(\mathrm{R}) \\
(\mathrm{daPa}) \\
(\text { mean } \pm \mathrm{SD})\end{array}$ & $\begin{array}{l}\text { Tympanogram type } \\
(\mathrm{L} / \mathrm{R})\end{array}$ & $\begin{array}{l}\text { Tympanogram type } \\
(\mathrm{L} / \mathrm{R}) \\
\mathrm{C} / \mathrm{A}\end{array}$ & Total \\
\hline $\begin{array}{l}\text { OA group } \\
\begin{array}{l}\text { Control } \\
\text { group }\end{array}\end{array}$ & $-49,72 \pm 33,23$ & $-45,97 \pm 31,50$ & 33 & 3 & 36 \\
$\begin{array}{l}\text { Total } \\
\text { p value }\end{array}$ & $-27,00 \pm 27,02$ & $-37,00 \pm 40,22$ & 30 & 0 & 30 \\
\hline \multicolumn{2}{l}{ OA; osteoarthritis, daPa; decapascals, R; right, L; left } & & 3 & 66 \\
\end{tabular}

OA; osteoarthritis, daPa; decapascals, R; right, L; left

Table 5. Stapes reflex

\begin{tabular}{lllll}
\hline Stapes reflex ( L / R ) & Yes/yes & Yes/no & No/yes & Total \\
\hline OA group & 34 & 1 & 1 & 36 \\
Control group & 30 & 0 & 0 & 30 \\
Total & 64 & 1 & 1 & 66 \\
\hline
\end{tabular}

OA; osteoarthritis, R; right, L; left 